\title{
Serum CD166: A novel biomarker for predicting nasopharyngeal carcinoma response to radiotherapy
}

\author{
Huan Lin ${ }^{1,2, *}$, Ze-Tan Chen ${ }^{1,2, *}$, Xiao-Dong Zhu ${ }^{1,2,3}$, Ling $\mathrm{Li}^{1,2,3}$, Song Qu ${ }^{1,2,3}$, Wei \\ Zhao $^{1,2}$, Fang Su ${ }^{1,2}$, Jing-Ni Wei ${ }^{1,2}$, Zhong-Guo Liang ${ }^{1,2}$, Qi-Yan Mo ${ }^{1,2}$, Jiang-Bo Wu ${ }^{1,2}$ \\ and Hui-Ling Meng ${ }^{1,2}$ \\ ${ }^{1}$ Department of Radiation Oncology, Affiliated Cancer Hospital of Guangxi Medical University and Cancer Institute of Guangxi \\ Zhuang Autonomous Region, Nanning, Guangxi 530021, P.R. China \\ ${ }^{2}$ Guangxi Key Laboratory of Early Prevention and Treatment for Regional High Frequency Tumor, Guangxi Medical University, \\ Nanning, Guangxi 530021, P.R. China \\ ${ }^{3}$ Key Laboratory of High-Incidence-Tumor Prevention and Treatment (Guangxi Medical University), Ministry of Education, \\ Nanning, Guangxi 530021, P.R. China \\ *These authors have contributed equally to this work \\ Correspondence to: Xiao-Dong Zhu, email: zhuxiaodong@gxmu.edu.cn \\ Keywords: nasopharyngeal carcinoma, radiosensitivity, radioresistance, biomarker, CD 166/ALCAM \\ Received: October 26, $2016 \quad$ Accepted: March 01, $2017 \quad$ Published: March 21, 2017 \\ Copyright: Lin et al. This is an open-access article distributed under the terms of the Creative Commons Attribution License (CC-BY), \\ which permits unrestricted use, distribution, and reproduction in any medium, provided the original author and source are credited.
}

\section{ABSTRACT}

The present study aimed to identify whether CD166 can be used as a biomarker for predicting the response of nasopharyngeal carcinoma (NPC) to radiotherapy. The serum concentration of CD166 in patients with NPC were detected by enzyme-linked immunosorbent assay. The secreted level of CD166 with radioresistant NPC was significantly higher than that with radiosensitive NPC. In vitro, the CD166 positive rate in the CNE2 cell membrane was significantly lower than that in the CNE2R cell membrane. The magneticactivated cell sorting technology was used to obtain CNE-2R-CD166(+) and CNE-2RCD166(-) cell lines. Then radiosensitivity, cell proliferation, and apoptosis were assessed using colony formation assay, cell counting kit 8 assay (CCK-8), and flow cytometry, respectively. The radiation sensitivity ratio was 1.28 , indicating that the CNE2R-CD166(-) cells had a stronger radiation sensitivity. The result of CCK- 8 assay indicated that the survival fraction of CNE2R-CD166(+) cells was significantly higher than that of CNE2RCD166(-) cells. The apoptotic rate of CNE2R-CD166(+) cells was significantly lower than that of CNE2R-CD166(-) cells. Our data demonstrate that the secreted protein CD166 may be can used as a biomarker for predicting the response of NPC to radiotherapy.

\section{INTRODUCTION}

Nasopharyngeal carcinoma (NPC) is one of the most common malignant tumors in Southeast Asia and southern China $[1,2]$. Because of its special anatomical position and the sensitivity to radiation, the radiation therapy is the main treatment method [3]. The local recurrence and distant metastasis of NPC in patients after radiotherapy is a bottleneck to restrict the curative effect and prognosis, and the radiation resistance is one of the main reasons $[4,5]$. Therefore, it is of great significance to search for molecular markers for predicting the sensitivity of NPC radiation therapy and for guiding the treatment of NPC and improve its prognosis.
The occurrence of radiation resistance is a multistage process, with multiple genes involved. The change in its gene level inevitably leads to changes in a large number of secretory proteins. Identification of differentially expressed proteins by proteomic methods is an effective and widely used technique [6]. In previous studies [7], the radioresistant CNE-2R and its parental $\mathrm{CNE}-2$ cell line were cultured in vitro. Some differentially secreted proteins were identified by proteomic techniques, and CD166 is one of them. The abnormal expression of CD166 according to Western blot analyses may serve as a potential biomarker for predicting NPC response to radiotherapy. 
The levels of secreted protein CD166 were detected in the serum of patients with NPC in this study to understand the relationship between radiosensitivity and clinical parameters. NPC cell line CNE2R and its parental cell line CNE2 were cultured in vitro, and the cell lines CNE2R-CD166(+) and CNE-2R-CD166(-) were obtained by the magnetic-activated cell sorting (MACS) technology. Then, radiosensitivity, cell proliferation, and apoptosis were assessed using colony formation assay, cell counting kit 8 (CCK-8) assay, and flow cytometry, respectively. The study aimed to investigate the relationship between the expression of secreted protein CD166/activated leukocyte cell adhesion molecule (ALCAM) and the sensitivity of NPC radiotherapy, and to identify whether it could be used as a biomarker for predicting the response of NPC to radiotherapy.

\section{RESULTS}

\section{Concentration of secreted protein CD166 was detected by ELISA}

ELISA showed that the expression of secreted protein CD166 in the serum of patients in the two groups had a significant difference $(P=0.03)$, as shown in

Figure 1. The concentration of secreted protein CD166 in the radioresistant group was higher than that in the radiosensitive group. No correlation was observed between CD166 expression and clinical stage, $\mathrm{T}$ stage, $\mathrm{N}$ stage, and other clinical parameters, include pathological type.

\section{Positive rate of CD166 was higher in the CNE2R cell membrane than in the CNE2 cell membrane}

The positive rate of CD166 in the CNE2R and CNE2 cell membranes was detected by flow cytometry before immunomagnetic separation. The positive rate of CD166 was significantly lower in the CNE2 cell membrane than in the CNE2R cell membrane $[(21.37 \pm 1.50) \%$ vs $(69.13 \pm 5.15) \%, P<0.01]$ (Figure 2A and Figure 2B). CNE2R-CD166(+) and CNE2R-CD166(-) cells were obtained by the MACS technology as mentioned earlier. The positive rate of CD166 at CNE2R-CD166(+) and CNE2R-CD166(-) cells was detected by flow cytometry directly. The positive rate of CD166 at CNE2R-CD166(+) cells and CNE2R-CD166(-) cells were 96.5\% and 9.1\% respectively (Figure $2 \mathrm{C}$ and Figure 2D), indicating that the sorting purity was high.

\section{Radiation sensitivity of the CNE2R-CD166(+) and CNE2R-CD166(-) cell lines}

Survival curves of the CNE2R-CD166(+) and CNE2R-CD166(-) cell lines were plotted using colony formation assays. Colony formation assays of the CNE2R-CD166(+) and CNE2R-CD166(-) cell lines were performed to evaluate radiosensitivity (Figure 3A). Figure $3 \mathrm{~B}$ shows that the survival curve of CNE2R-CD166(+) cells was higher than that of CNE2R-CD166(-) cells. The main parameters are shown in Table 1 . From the $\mathrm{D}_{0}($ dose of radiation producing a 37\% survival rate), Dq (quasithreshold dose required for cell damage) and $\mathrm{SF}_{2}$ (survival fraction at $2 \mathrm{~Gy}$ ) values, it can be concluded that CNE2RCD166(-) cells had a greater decrease in the surviving fractions when compared with CNE2R-CD166(+) cells. When the data were analyzed by the multi-target singlehit model. $\mathrm{SF}=1-\left(1-\mathrm{e}^{-D / D 0}\right)^{N}$, by calculating the sensitization enhancement ratio (SER), we used the $D_{0}$ of CNE2R-CD166(-) cells divided by the D0 of CNE2R$\mathrm{CD} 166(+)$ cells, the values of $\mathrm{SER}_{\mathrm{D} 0}=1.28>1$, suggesting that CNE2R-CD166(-) cells were more sensitive to radiation compared with CNE2R-CD166(+) cells.

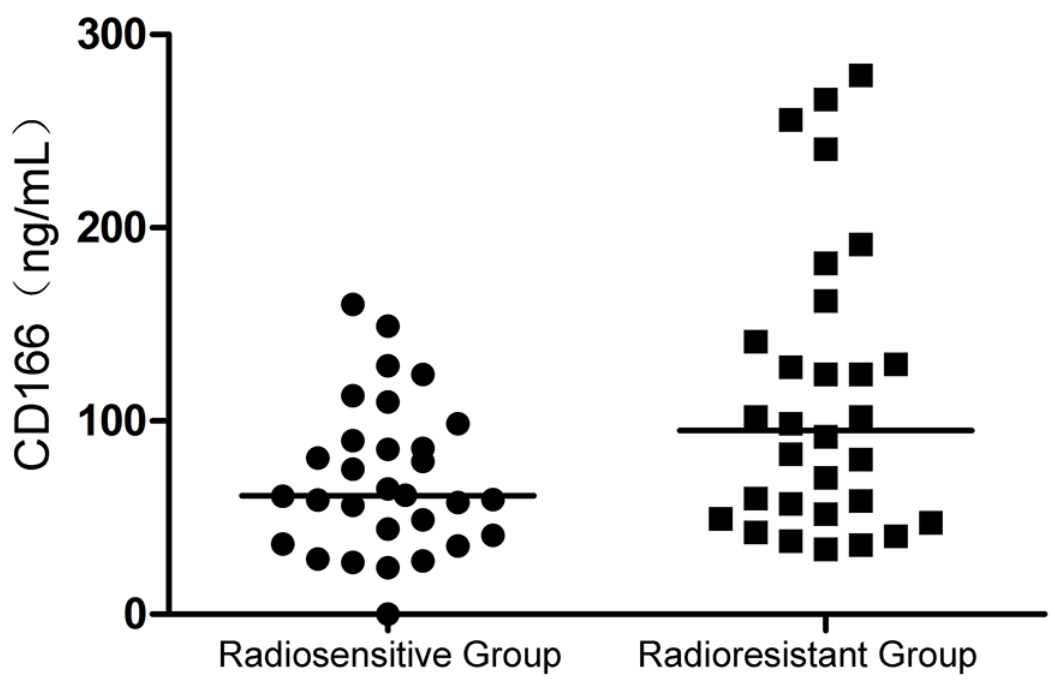

Figure 1: Concentration of secreted protein CD166 was higher in the radioresistant group than that in the radiosensitive group; the difference had statistical significance $(P=\mathbf{0 . 0 3})$. 


\section{Cell proliferation after irradiation was examined by the CCK-8 assay}

The comparison of survival fraction between CNE2RCD166(+) cells and CNE2R-CD166(-) cells at different times after 10 Gy irradiation is shown in Table 2. Figure 4 shows that the survival fraction of CNE2R-CD166(+) cells was significantly higher than that of CNE2R-CD166(-) cells at 24, 48, and $72 \mathrm{~h}$, respectively, indicating that CNE2R-CD166(-) cells were more sensitive to radiation compared with CNE2R-CD166(+) cells.

\section{Flow cytometry detected the apoptosis of CNE- 2R-CD166(+) and CNE-2R-CD166(-) cells}

Cell apoptosis was measured by flow cytometry. No significant difference was found between CNE2RCD166(+) and CNE2R-CD166(-) cells $[(4.83 \pm 0.68) \%$ vs $(5.47 \pm 0.95) \%, P>0.05]$ before irradiation. However, a significant difference was found between CNE2RCD166(+) and CNE2R-CD166(-) cells [(16.13 \pm 1.82$) \%$ vs $(31.57 \pm 0.95) \%, P>0.05]$ after $10 \mathrm{~Gy}$ irradiation for $24 \mathrm{~h}$.

\section{DISCUSSION}

The radiotherapy technology for treating NPC has improved in recent years. However, still more than $15 \%$ of patients have NPC recurrence [8]. Radioresistance is one of the main factors in the current clinical management of NPC $[4,5]$. A number of studies have been conducted on resistance-related factors, such as overexpression of DNA repair proteins [9], abnormal expression of epidermal growth factor receptor (EGFR) [10], autophagy [11-13], angiogenesis [14], and cancer stem cells [15]. However, no effective serum biomarkers are available at present for predicting the radiosensitivity of NPC. The proteomic technology is an effective method to search for effective serum biomarkers. In previous studies [7], some differentially secreted proteins were identified by proteomic techniques. CD166 is one of the 26 differentially secreted proteins, which is of interest.

CD166, also known as ALCAM, is a highly conserved 110-kDa multidomain transmembrane type-1 glycoprotein belonging to the immunoglobulin superfamily, which was first described as a CD6 ligand on leukocytes. It plays an important role in some biological activities, including proliferation, T-cell activation, and angiogenesis [16]. Through homophilic and heterophilic adhesion, CD166 mediates the interaction between cells and participates in many kinds of pathological and physiological processes [17]. It has been confirmed that CD166 is abnormally expressed in a variety of tumor cells and plays an important role in tumor invasion and metastasis, such as breast cancer [18], liver cancer [19], stomach cancer [20], colon cancer [21], malignant melanoma [22], salivary gland tumor [23], prostate cancer [24], and so forth. It is also thought to be one of the markers of cancer stem cells [25]. A study [26] showed that the expression rate of CD166 in head and neck squamous cell carcinomas (HNSCCs, including oral cavity, oropharynx, and hypopharynx/larynx) was up to $70.32 \%$, and CD166 expression was significantly more frequent in malignant tissues compared with nonmalignant tissues. Another study of HNSCCs [27] demonstrated that CD166 was a valuable cell surface marker for the enrichment of HNSCC stem cells and the level of CD166 expression was
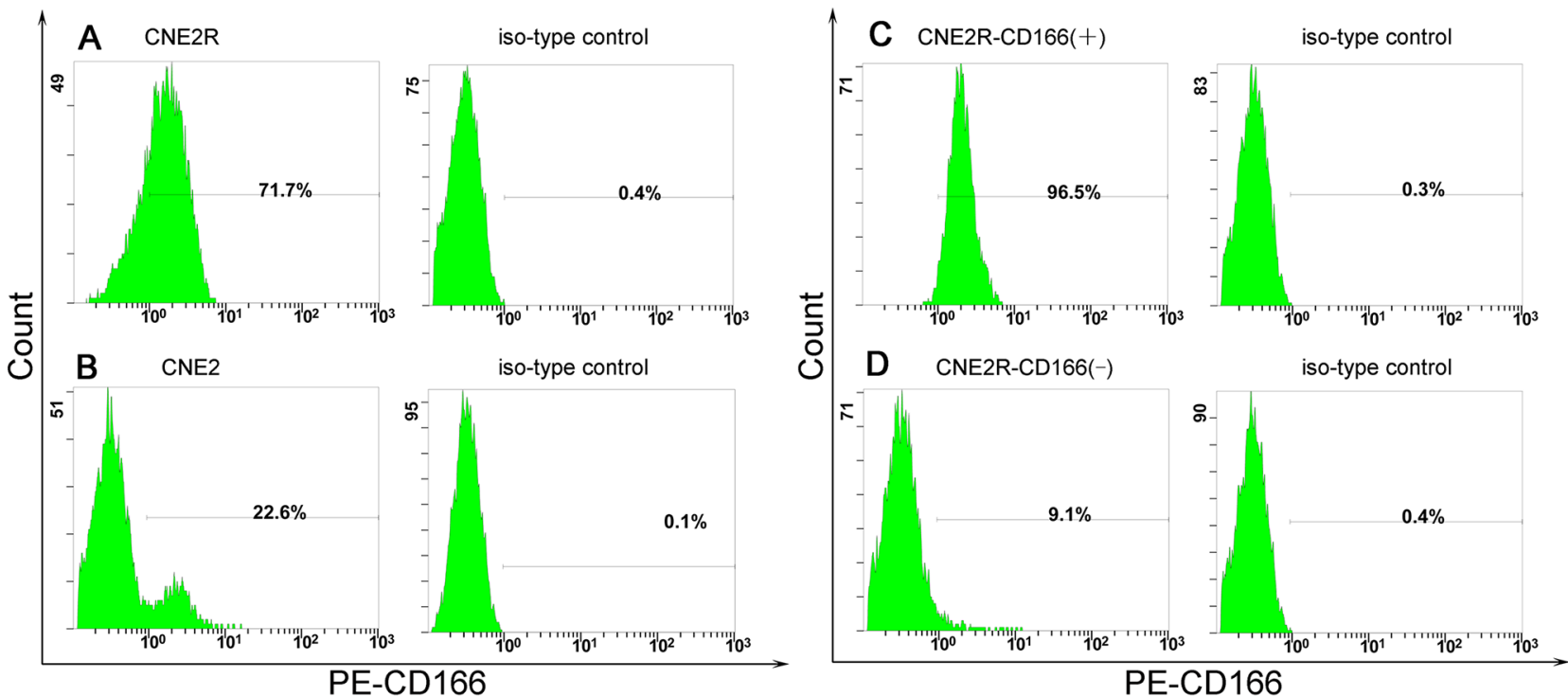

Figure 2: (A) Positive rates of CD166 in the CNE2R cell membrane was $(69.13 \pm \mathbf{5 . 1 5}) \%$. (B) Positive rates of CD166 in the CNE2 cell membrane was $(21.37 \pm 1.50) \%$. ${ }^{*}$ The positive rate of CD166 at CNE2R was significantly higher than the positive rates of CD166 at CNE2 ( $\mathrm{P}<0.05$ ). (C) Positive rates of CD166 at CNE2R-CD166(+) cells was 96.5\% after immunomagnetic separation. (D) Positive rates of CD166 at CNE2R-CD166(-) was $9.1 \%$ after immunomagnetic separation. 
associated with the tumor recurrence rate. However, the two aforementioned studies did not include NPC. In 1976 [28], the cancer stem cell theory was first proposed by Nowell: stem cells are rare in most tissues, and cancer is thought to be a kind of disease of stem cells [29]. Furthermore, the existence of cancer stem cells is one of the causes of resistance [15]. However, in this study, the positive rate of CD166 in CNE2 was $(21.37 \pm 1.50) \%$, which did not support the hypothesis that it is the stem cell marker of NPC.

Moreover, CD166 and EGFR are involved in proteinprotein interactions [30]. EGFR, a key member of the tyrosine kinase receptor family, is a transmembrane tyrosine kinase protein of $170 \mathrm{kDa}$ encoded by EGFR gene. It is involved in the occurrence and development of malignant tumors by regulating the cell cycle, apoptosis, and so on [31]. EGFR can significantly promote cell proliferation [32]. EGFR gene silencing can inhibit the growth of NPC cells, increase cell apoptosis, and increase the sensitivity of cells to chemotherapy [33]. The overexpression of EGFR was also associated with a poor effect of tumor radiotherapy [34]. In head and neck cancer cells, high levels of EGFR are associated with radiation resistance, whereas the anti-EGFR monoclonal antibody can improve the radiosensitivity of cells $[35,36]$. In advanced or recurrent NPC, the expression of EGFR has a direct effect on the radiosensitivity of cells. Patients whose tumors expressed low levels of CD166 performance were more sensitive to radiation compared with those whose tumors expressed
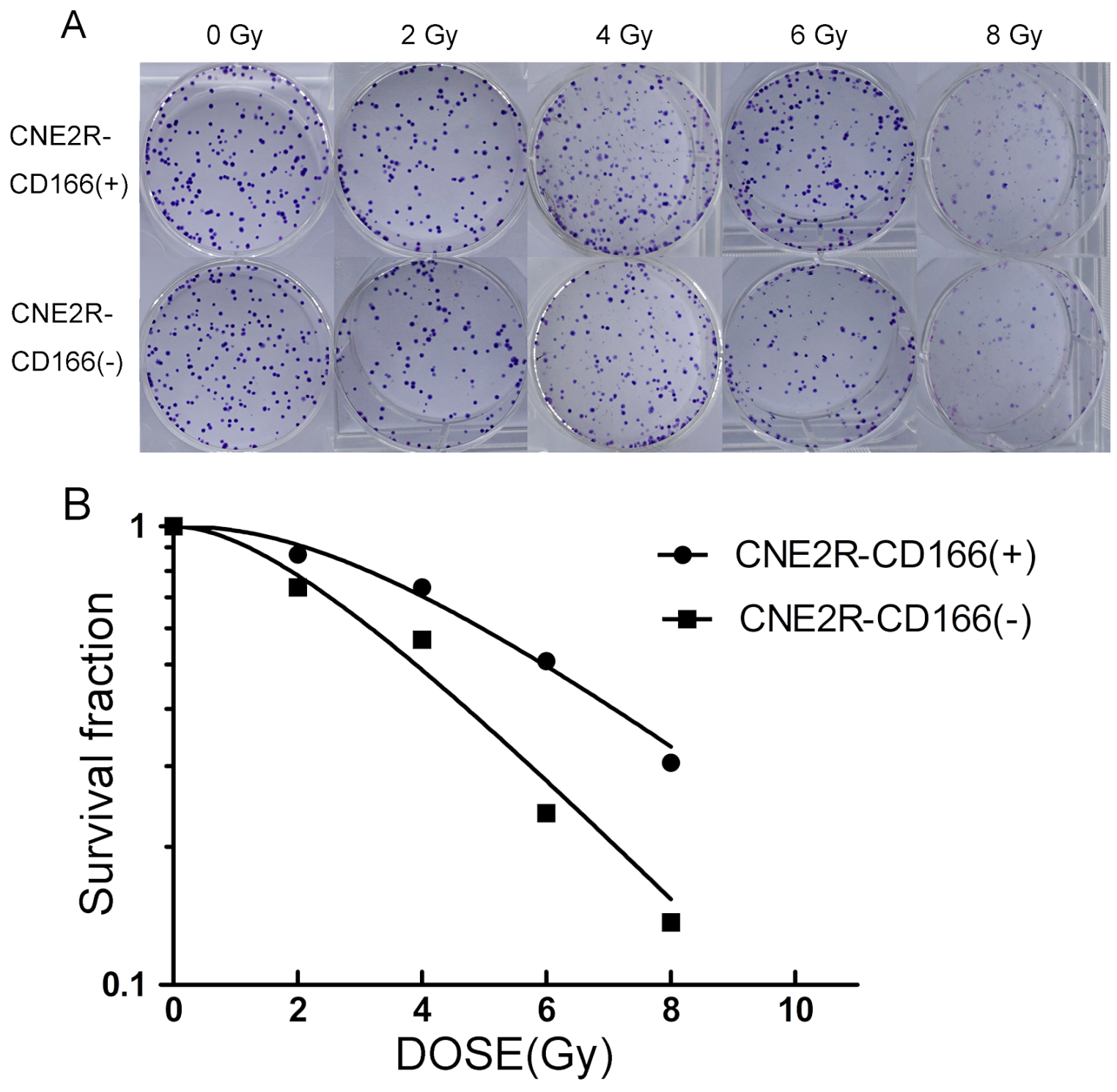

Figure 3: Colony formation assays for radiosensitivity. (A) Colony formation assays of the CNE2R-CD166(+) and CNE2RCD166(-) cell lines were performed to evaluate radiosensitivity. (B) Fit curves were analyzed using GraphPad Prism 5.0 software. 
Table 1: Correlation parameters in the multitarget single-hit model

\begin{tabular}{lccc}
\hline Group & $\mathbf{S F}_{\mathbf{2}}$ & $\mathbf{D}_{\mathbf{0}}(\mathbf{G y})$ & $\mathbf{D q}(\mathbf{G y})$ \\
\hline CNE2R-CD166(+) & 0.88 & 4.39 & 4.08 \\
CNE2R-CD166(-) & 0.80 & 3.44 & 2.76 \\
\hline
\end{tabular}

Table 2: Comparison of survival fraction (\%) between two groups

\begin{tabular}{lcccc}
\hline Groups & $\mathbf{0 ~ h}$ & $\mathbf{2 4} \mathbf{~ h}$ & $\mathbf{4 8 ~} \mathbf{~}$ & $\mathbf{7 2} \mathbf{~ h}$ \\
\hline CNE2R-CD166(+) & 100 & $81.16 \pm 2.84$ & $74.64 \pm 1.66$ & $65.83 \pm 2.41$ \\
CNE2R-CD166(-) & 100 & $67.24 \pm 2.83$ & $53.60 \pm 4.19$ & $46.68 \pm 2.63$ \\
$P$ & - & 0.004 & 0.001 & 0.001 \\
\hline
\end{tabular}

low high levels of CD166 [37]. The Ras/Raf/MEK/MAPK and $\mathrm{PI} 3 \mathrm{~K} / \mathrm{AKT} / \mathrm{mTOR}$ pathways have been well studied among the downstream signaling pathways activated by EGFR. CD166 may play an important role in antiradiation activity through the EGFR signaling pathway. Therefore, the gene silencing of CD166 in NPC cells may be one of the effective strategies to enhance the radioresistance of cells and is worth further exploration.

The concentration of secreted protein CD166 was detected by ELISA in the present study. The concentration of secreted protein CD166 was significantly higher in the radioresistant group than in the radiosensitive group (Figure 1). No correlation was found between CD166 expression and clinical stage, $\mathrm{T}$ stage, $\mathrm{N}$ stage, and other clinical parameters, but it was not due to the lack of clinical samples. Next, the flow cytometric analysis showed that the CD166 positive rate in the CNE2 cell membrane was significantly higher than that in the CNE2R cell membrane (Figure 2). CNE2R-CD166(+) and CNE2R-CD166(-) cells were obtained according to the MACS technology for the following experiments. Radiosensitivity, cell proliferation, and apoptosis were assessed using colony formation assay, CCK-8 assay, and flow cytometry, respectively. The result of colony formation assay indicated that CNE2R-CD166(+) cells were more radioresistant compared with CNE2RCD166(-) cells (Figure 3 and Table 2). The result of CCK-8 assay indicated that the survival fraction of CNE2R-CD166(+) cells was significantly higher than that of CNE2R-CD166(-) cells (Figure 4 and Table 3 ). The main mechanism of tumor radiotherapy was to induce cell apoptosis [38]. The apoptotic rates of CNE2R-CD166(+) cells after irradiation was significantly lower than that of CNE2R-CD166(-) cells in this study (Figure 5).

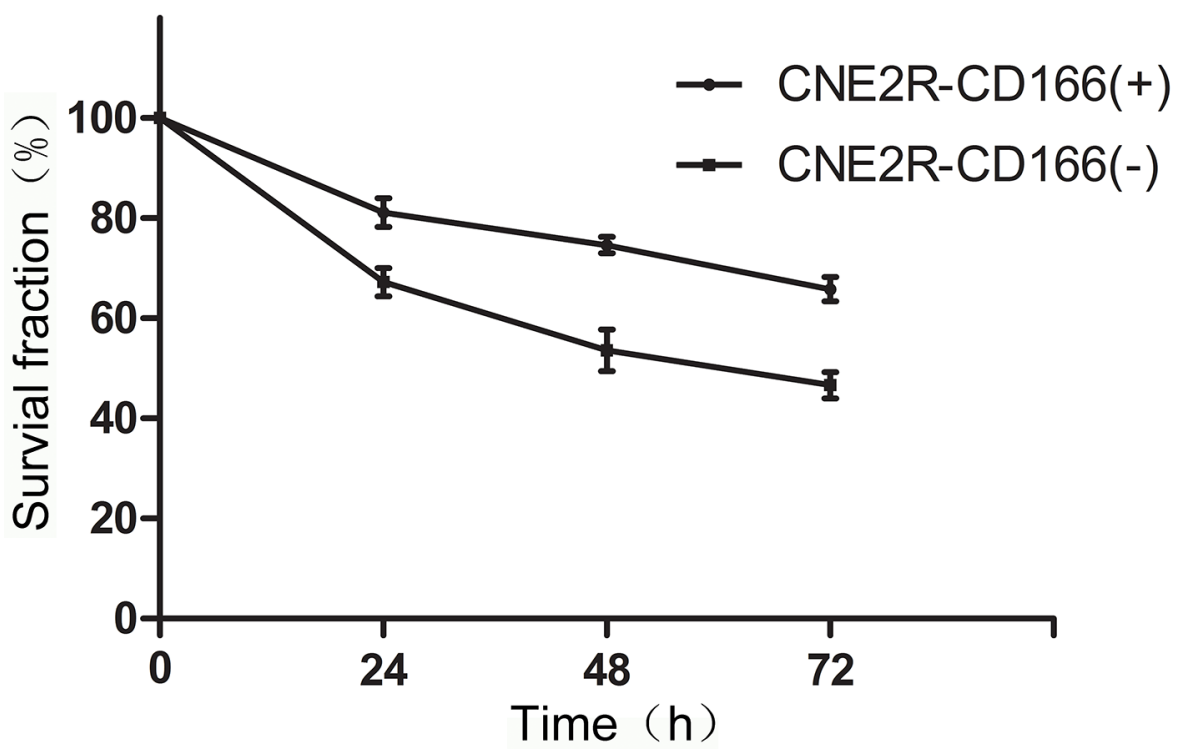

Figure 4: Survival curve after irradiation was detected by the CCK-8 assay in CNE2R-CD166(+) and CNE2R-CD166(-) cells. The survival fraction of CNE2R-CD166(+) cells was significantly higher than that of CNE2R-CD166(-) cells at 24, 48, and 72 h. 
Table 3: Comparison of clinical-pathological parameters in the two groups of nasopharyngeal carcinoma

\begin{tabular}{|c|c|c|c|c|}
\hline Classification & & $\begin{array}{l}\text { Radioresistant group } \\
(n=30)\end{array}$ & $\begin{array}{c}\text { Radiosensitive group } \\
(n=30)\end{array}$ & $* p$ \\
\hline \multirow[t]{2}{*}{ Pathologic type } & Differentiated & 5 & 6 & $>0.05$ \\
\hline & Undifferentiated & 25 & 24 & \\
\hline \multirow[t]{4}{*}{ T Stage } & $\mathrm{T} 1$ & 2 & 3 & $>0.05$ \\
\hline & $\mathrm{T} 2$ & 4 & 10 & \\
\hline & $\mathrm{T} 3$ & 9 & 6 & \\
\hline & $\mathrm{T} 4$ & 15 & 11 & \\
\hline \multirow[t]{4}{*}{ N Stage } & No & 0 & 0 & $>0.05$ \\
\hline & N1 & 15 & 10 & \\
\hline & N2 & 13 & 16 & \\
\hline & N3 & 2 & 4 & \\
\hline \multirow[t]{4}{*}{ Clinical stage } & I & 0 & 0 & $>0.05$ \\
\hline & II & 3 & 6 & \\
\hline & III & 11 & 9 & \\
\hline & $\mathrm{IVa}+\mathrm{IVb}$ & 16 & 15 & \\
\hline \multirow[t]{2}{*}{ Sex } & Male & 20 & 25 & $>0.05$ \\
\hline & Female & 10 & 5 & \\
\hline \multirow[t]{2}{*}{ Age } & $<50$ & 17 & 16 & $>0.05$ \\
\hline & $\geq 50$ & 13 & 14 & \\
\hline Hemoglobin $(\mathrm{g} / \mathrm{L})$ & & $132.6 \pm 16.89$ & $131.50 \pm 16.30$ & $>0.05$ \\
\hline GTVnx (Gy) & & $71.76 \pm 0.92$ & $71.52 \pm 1.05$ & $>0.05$ \\
\hline GTVnd (Gy) & & $68.34 \pm 1.80$ & $68.25 \pm 2.69$ & $>0.05$ \\
\hline CTV1 (Gy) & & $60.73 \pm 0.98$ & $60.33 \pm 0.78$ & $>0.05$ \\
\hline CTV2 (Gy) & & $54.66 \pm 0.88$ & $54.23 \pm 0.80$ & $>0.05$ \\
\hline
\end{tabular}

*The difference between the two groups was not statistically significant.

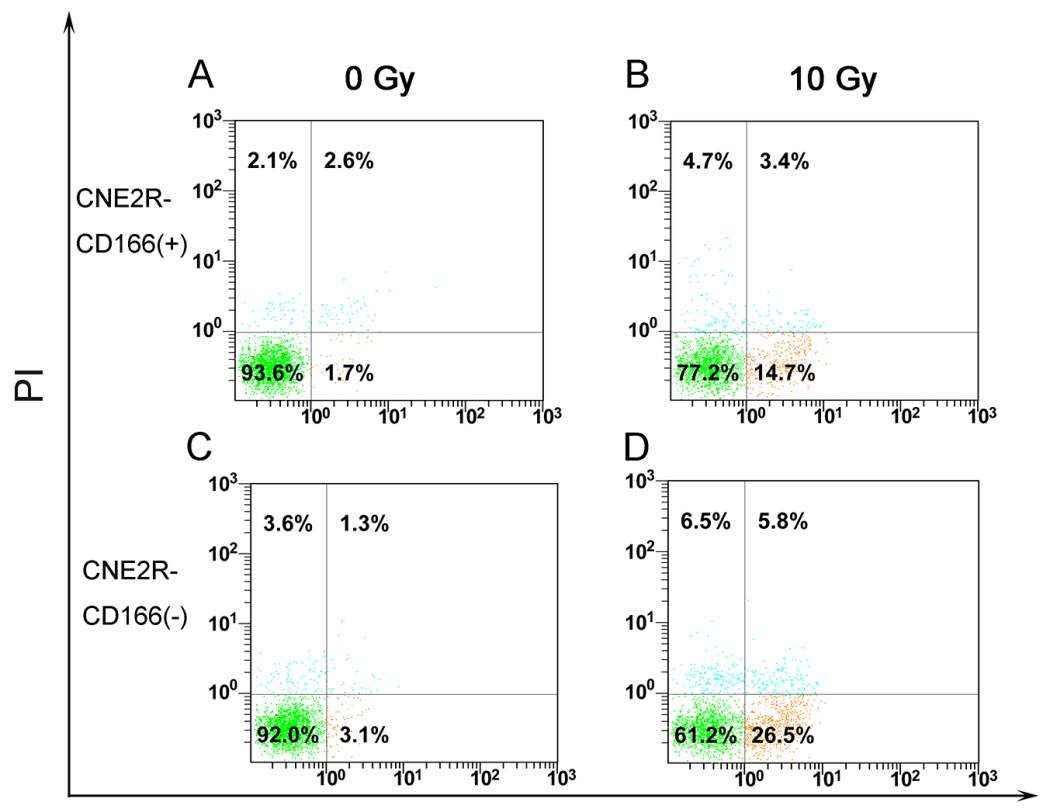

FITC Annexin V

Figure 5: (A) Apoptotic rates of CNE2R-CD166(+) cells before irradiation. (B) Apoptotic rates of CNE2R-CD166 $(+)$ cells after 10 Gy irradiation. (C) Apoptotic rates of CNE2R-CD166(-) cells before irradiation. (D) Apoptotic rates of CNE2R-CD166(-) cells after 10 Gy irradiation. 
In conclusion, CD166 is a novel biomarker for predicting NPC response to radiotherapy. The individual treatment should be planned according to the expression of CD166 in the serum of NPC before treatment.

\section{MATERIALS AND METHODS}

\section{Serum sample}

A total of 60 NPC serum samples obtained from the Affiliated Cancer Hospital of Guangxi Medical University from March 2015 to October 2013 were used in this study. All the patients were diagnosed by histopathology, and TNM stage designation was according to the definitions of the seventh edition of the Union of International Cancer Control American Joint Committee on Cancer staging criteria. All the patients had no distant metastasis and did not receive radiotherapy or chemotherapy before the acquisition of serum. The patients were treated with $6 \mathrm{MV}$ $\mathrm{X}$-radiation from an Elekta linear accelerator (Precise 1120; Elekta Instrument AB, Stockholm, Sweden) at a dose rate of $220 \mathrm{cGy} / \mathrm{min}$. After 7-8 weeks of radiation therapy, the patients were divided into the radiosensitive group and the radioresistant group based on the therapeutic effect [39]. Patients with radioresistant NPC were defined as the ones with persistent disease (incomplete regression of primary tumor and/or neck lymph nodes) at $>3$ months or with the local recurrent disease at the nasopharynx and/or neck lymph nodes at $\leq 12$ months after completion of radiotherapy. Patients with radiosensitive NPC were defined as the ones without the local residual lesions (complete regression) at $>3$ months and without local recurrent disease at $>12$ months after completion of radiotherapy. Each group included 30 patients, and the difference between the 2 groups was not statistically significant. The detailed clinical data are shown in Table 3.

\section{Enzyme-linked immunosorbent assay for the determination of serum $\mathrm{C} 166$ concentration}

CD166 concentrations in the serum of patients with NPC were quantified using an ALCAM (human) Enzymelinked Immunosorbent Assay (ELISA) Kit (Catalog Number KA1692,Abnova). All reagents, samples, and standards were prepared as instructed. All standards and samples were run in duplicate and the dilution for serum is 200 fold. Add $100 \mu \mathrm{L}$ standard or sample to each well. Incubate 2.5 hours at room temperature. Discard the solution and wash 4 times with 1x Wash Solution. Add $100 \mu \mathrm{L}$ prepared biotin antibody to each well and Incubate 1 hour at room temperature. Repeat the wash steps, then add $100 \mu \mathrm{L}$ prepared Streptavidin solution and incubate 45 minutes at room temperature. Repeat the wash steps again. Add $100 \mu \mathrm{L}$ TMB One-Step Substrate Reagent to each well and incubate 30 minutes at room temperature. Add 50 $\mu \mathrm{L}$ Stop Solution to each well. Read at a microplate reader
(Bio-Rad, Hercules, CA, USA) at $450 \mathrm{~nm}$ immediately. The mean absorbance for each set of duplicate standards, controls, and samples was calculated. The standard curve was plotted using SigmaPlot software to calculate the CD166 concentration of each sample.

\section{Cell lines and culture}

CNE-2, a human NPC cell line, was constructed by the Cancer Hospital Chinese Academy of Medical Science and Guangdong Medical University and purchased from the Cancer Hospital of Shanghai Fudan University. The radioresistant cell line CNE2R was obtained from CNE2 after exposure to radiation at a total dose of $64 \mathrm{~Gy}$ in 1 year by the Research Department, Affiliated Cancer Hospital of Guangxi Medical University [40]. CNE-2 and CNE2R cells were cultured in RPMI-1640 medium (Hyclone, USA) with the addition of $10 \%$ fetal bovine serum(FBS) (Gibco, USA), penicillin (100 U/ml) and streptomycin $(100 \mu \mathrm{g} / \mathrm{ml})$, and were cultured in a humidified $5 \% \mathrm{CO}_{2}$ atmosphere at $37^{\circ} \mathrm{C}$.

\section{Positive rate of CD166 in the cell membrane was detected by flow cytometry, and the MACS technology was used to sort cells}

CNE2 and CNE2R cells were cultured as previously until the cells grew to $80 \%$ confluence. The cells were digested with $0.25 \%$ trypsin- $0.02 \%$ EDTA. They were washed twice with phosphate-buffered saline (PBS) to remove any adherent serum, and $5 \times 10^{6}$ cells were resuspended in $100 \mu \mathrm{L}$ of PBS. The cells were labeled with $10 \mu \mathrm{L}$ of phycoerythrin (PE)-conjugated anti-CD166 antibody (BD Pharmingen, $\mathrm{CA}$, USA), incubated for 10 min in the dark in the refrigerator $\left(2^{\circ} \mathrm{C}-8^{\circ} \mathrm{C}\right)$, and detected using a FC500 flow cytometry systems(Beckman Coulter). Isotype-matched mouse antibodies served as controls. The experiments were performed three times.

NEXT, We use MiniMASC ${ }^{\text {TM }}$ Starting Kit (Miltenyi Biotec, Germany) for cell sorting. When incubate for 10 minutes in the dark in the refrigerator $\left(2-8{ }^{\circ} \mathrm{C}\right)$ as previously, wash cells to remove unbound primary antibody. Aspirate supernatant completely and resuspend cell pellet in $80 \mu \mathrm{L}$ of buffer per $10^{7}$ total cells. Add $20 \mu \mathrm{L}$ of Anti-PE MicroBeads per $10^{7}$ total cells. Mix well and incubate for 15 minutes in the refrigerator $\left(2-8^{\circ} \mathrm{C}\right)$. Wash cells by adding $2 \mathrm{~mL}$ of buffer per $10^{7}$ cells and centrifuge at $300 \times \mathrm{g}$ for $10 \mathrm{~min}$. Resuspend up to $10^{8}$ total cells in $500 \mu$ l of buffer. After magnetic labeling, cells are passed through a MACS Column which is placed in the strong permanent magnet of the MACS Separator. Unlabeled cells passed through while magnetically labebled cell are retained in the column. Remove column from the separator and place it on a suitable collection tube, then pipette appropriate amount of buffer onto the column. Immediately flush out the magnetically labeled cells by firmly pushing the plunger into the column. 
In order to verify the purity of the separation, after separation the PE-labeled cells were detected by flow cytometry directly. Then CNE2R-CD166 (+),CNE2RCD166 (-) cells were cultured for further experiments.

\section{Colony formation assay}

The colony formation assay is the standard to detect the sensitivity of cells to radiation [41]. Aliquots consisting of 200, 200, 400, 600 and 1,000 CNE2R-CD166(+) and CNE2R-CD166(-) cells were plated into five 6-well plates and individually exposed to doses of $0,2,4,6$, and 8 Gy with 6 MV X-rays from an Elekta linear accelerator (Precise 1120; Elekta Instrument AB, Stockholm, Sweden) with a dose rate of $220 \mathrm{cGy} / \mathrm{min}$. Culture solution was replaced every 2-3 days after irradiation until twelfth days. Then the colonies were fixed with carbinol for $20 \mathrm{~min}$ and stained with $0.1 \%$ Giemsa (Solarbio, Pe King) for $30 \mathrm{~min}$. Colonies (defined as any colony with $\geq 50$ cells) were scored as survivors. All experiments were performed three times. The dose responses were analyzed using the multitarget single-hit model, $\mathrm{SF}=1-\left(1-\mathrm{e}^{-D / D 0}\right)^{N}$, where $\mathrm{D}$ is the single radiation dose, $\mathrm{D}_{0}$ is the single radiation dose of radiation producing a $37 \%$ survival rate, $\mathrm{SF}$ is the survival fraction at dose $\mathrm{D}$ and $\mathrm{N}$ is the radiobiological parameter.

\section{CCK-8 assay}

Cell viability in response to irradiation was detected by the CCK-8 assay (Dojindo, Japan). Cells were plated in four 96-well plates at a density of $4 \times 10^{3}$ cells/well and allowed to attach for $24 \mathrm{~h}$. The cells were then irradiated with $6 \mathrm{MV}$ X-radiation at a dose of $10 \mathrm{~Gy}$. After culturing for $0,24,48$, and $72 \mathrm{~h}, 10 \mu \mathrm{L}$ of $10 \mathrm{mg} /$ $\mathrm{mL}$ CCK-8 solution was added to each well and cultured in a humidified $5 \% \mathrm{CO}_{2}$ atmosphere at $37^{\circ} \mathrm{C}$ for $2 \mathrm{~h}$. The absorbance of each well was measured using a microplate reader at $450 \mathrm{~nm}$. Five wells for each time point, all experiments were performed three times. OD is the mean absorbance after remove a maximum and a minimum OD values. Cell survival fraction was calculated using the formula:Survival fraction $(\%)=\mathrm{OD} / \mathrm{OD}_{0 \mathrm{~h}} \times 100 \%$.

\section{Apoptosis analysis}

CNE-2R-CD166(+) and CNE-2R-CD166(-) cells were seeded in 6-well culture plates at $5 \times 10^{5}$ cells/ well and allowed to attach for $24 \mathrm{~h}$. Then, the cells were irradiated with $6 \mathrm{MV}$ X-radiation at a dose of $10 \mathrm{~Gy}$. After culturing in a humidified $5 \% \mathrm{CO}_{2}$ atmosphere at $37^{\circ} \mathrm{C}$ for $24 \mathrm{~h}$, the cells were collected and resuspended in PBS and stained first with Annexin- $\mathrm{V}$-fluorescein isothiocyanate (FITC) for $10 \mathrm{~min}$ at room temperature and then with propidium iodide for $10 \mathrm{~min}$ in the dark, according to the manufacturer's instructions of the FITC Annexin V apoptosis detection kit I (BD Pharmingen, USA). The cells were analyzed immediately on the FC500 flow cytometry systems. All samples were assayed in triplicate.

\section{Statistical analysis}

Data were presented as the mean \pm standard deviation(SD). Statistical analyses were performed using SPSS 17.0 (SPSS, IL, USA) or GraphPad Prism 5.0 software. The Wilcoxon rank-sum test was used to analyze the CD166 expression in different groups. The independent-samples $t$ test was used to analyze the cell proliferation and apoptotic rates. All statistical tests were two sided. A $p$ value less than 0.05 indicated statistically significant differences.

\section{Authors' contributions}

Xiao-Dong Zhu and Ze-Tan Chen conceived and designed the study. Huan Lin, Qi-Yan Mo, Jiang-Bo Wu and Hui-Ling Meng performed the experiments. Huan Lin wrote the paper. Ling Li, Song Qu, Wei Zhao and Fang Su reviewed and edited the manuscript. Jing-Ni Wei and Zhong-Guo Liang analyzed experimental results. All authors read and approved the manuscript.

\section{Ethics statement}

This study was conducted with the approval of the ethical and scientific committees of Affiliated Cancer Hospital of Guangxi Medical University. Written informed consent was obtained from all participants in the study.

\section{ACKNOWLEDGMENTS}

The present study was supported by grants from the Natural Science Foundation of China (81360343) and the Key Laboratory of High-Incidence-Tumor Prevention and Treatment (Guangxi Medical University),Ministry of Education,Independent Research Project(Contract number: GKE2015-ZZ09).

\section{CONFLICTS OF INTEREST} interest.

The authors disclose no potential conflicts of

\section{REFERENCES}

1. Tang LL, Chen WQ, Xue WQ, He YQ, Zheng RS, Zeng YX, Jia WH. Global trends in incidence and mortality of nasopharyngeal carcinoma. Cancer Lett. 2016; 374: 22-30.

2. Ho JH. An epidemiologic and clinical study of nasopharyngeal carcinoma. Int J Radiat Oncol Biol Phys. 1978; 4: 182-198.

3. Chan AT. Current treatment of nasopharyngeal carcinoma. Eur J Cancer. 2011; 47 Suppl 3: S302-303. 
4. Xu J, Ai Q, Cao H, Liu Q. MiR-185-3p and miR-324-3p predict radiosensitivity of nasopharyngeal carcinoma and modulate cancer cell growth and apoptosis by targeting SMAD7. Med Sci Monit. 2015; 21: 2828-2836.

5. Zhu H, Zhu X, Cheng G, Zhou M, Lou W. Downregulation of microRNA-21 enhances radiosensitivity in nasopharyngeal carcinoma. Exp Ther Med. 2015; 9: 2185-2189.

6. Chen ZT, Liang ZG, Zhu XD. A Review: Proteomics in Nasopharyngeal Carcinoma Int J Mol Sci. 2015; 16: 15497-15530.

7. Chen ZT, Li L, Guo Y, Qu S, Zhao W, Chen H, Su F, Yin J, Mo QY, Zhu XD. Analysis of the differential secretome of nasopharyngeal carcinoma cell lines CNE-2R and CNE-2. Oncol Rep. 2015; 34: 2477-2488.

8. Yoshizaki T, Ito M, Murono S, Wakisaka N, Kondo S, Endo K. Current understanding and management of nasopharyngeal carcinoma. Auris Nasus Larynx. 2012; 39: 137-144.

9. Zafar F, Seidler SB, Kronenberg A, Schild D, Wiese C. Homologous recombination contributes to the repair of DNA double-strand breaks induced by high-energy iron ions. Radiat Res. 2010; 173: 27-39.

10. Chen W, Hu GH. Biomarkers for enhancing the radiosensitivity of nasopharyngeal carcinoma. Cancer Biol Med. 2015; 12: 23-32.

11. Chen ZT, Zhao W, Qu S, Li L, Lu XD, Su F, Liang ZG, Guo SY, Zhu XD. PARP-1 promotes autophagy via the AMPK/ mTOR pathway in CNE-2 human nasopharyngeal carcinoma cells following ionizing radiation, while inhibition of autophagy contributes to the radiation sensitization of CNE-2 cells. Mol Med Report. 2015; 12: 1868-1876.

12. Chaachouay H, Ohneseit P, Toulany M, Kehlbach R, Multhoff G, Rodemann HP. Autophagy contributes to resistance of tumor cells to ionizing radiation. Radiother Oncol. 2011; 99: 287-292.

13. Zhou ZR, Zhu XD, Zhao W, Qu S, Su F, Huang ST, Ma JL, Li XY. Poly(ADP-ribose) polymerase-1 regulates the mechanism of irradiation-induced CNE-2 human nasopharyngeal carcinoma cell autophagy and inhibition of autophagy contributes to the radiation sensitization of CNE-2 cells. Oncol Rep. 2013; 29: 2498-2506.

14. Chen $\mathrm{Z}, \mathrm{Xu} \mathrm{XH}$. Combining antiangiogenic therapy and radiation in nasopharyngeal carcinoma. Saudi Med J. 2015; 36: 659-664.

15. Moncharmont C, Levy A, Gilormini M, Bertrand G, Chargari C, Alphonse G, Ardail D, Rodriguez-Lafrasse C, Magné N. Targeting a cornerstone of radiation resistance: Cancer stem cell. Cancer Lett. 2012; 322: 139-147.

16. Zimmerman AW, Joosten B, Torensma R, Parnes JR, van Leeuwen FN, Figdor CG. Long-term engagement of CD6 and ALCAM is essential for T-cell proliferation induced by dendritic cells. Blood. 2006; 107: 3212-3220.
17. van Kempen LC, Nelissen JM, Degen WG, Torensma R, Weidle UH, Bloemers HP, Figdor CG, Swart GW. Molecular basis for the hemophilic activated leukocyte cell adhesion molecule (ALCAM)-ALCAM interaction. J Biol Chem. 2001; 276: 25783-25790.

18. Burkhardt M, Mayordomo E, Winzer KJ, Fritzsche F, Gansukh T, Pahl S, Weichert W, Denkert C, Guski H, Dietel $\mathrm{M}$, Kristiansen G. Cytoplasmic overexpression of ALCAM is prognostic of disease progression in breast cancer. J Clin Pathol. 2006; 59: 403-409.

19. Ma LF, Lin JF, Qiao YX, Weng WH, Liu WW, Wang JY, Sun FY. Serum CD166: A novel hepatocellular carcinoma tumor marker. Clin Chim Acta. 2015; 441: 156-162.

20. Ishigami S, Ueno S, Arigami T, Arima H, Uchikado Y, Kita Y, Sasaki K, Nishizono Y, Omoto I, Kurahara H, Matsumoto M, Kijima Y, Natsugoe S. Clinical implication of CD166 expression in gastric cancer. J Surg Oncol. 2011; 103: 57-61.

21. Weichert W, Knosel T, Bellach J, Dietel M, Kristiansen G. ALCAM/CD166 is overexpressed in colorectal carcinoma and correlates with shortened patient survival. J Clin Pathol. 2004; 57: 1160-1164.

22. van Kempen LC, van den Oord JJ, van Muijen GN, Weidle UH, Bloemers HP, Swart GW. Activated leukocyte cell adhesion molecule/CD166, a marker of tumor progression in primary malignant melanoma of the skin. Am J Pathol. 2000; 156: 769-774.

23. Andisheh-Tadbir A, Ashraf MJ, Khademi B, Ahmadi S. Clinical implication of CD166 expression in salivary gland tumor. Tumor Biology. 2015; 36: 2793-2799.

24. Kristiansen G, Pilarsky C, Wissmann C, Stephan C, Weissbach L, Loy V, Loening S, Dietel M, Rosenthal A. ALCAM/CD166 is up-regulated in low-grade prostate cancer and progressively lost in high-grade lesions. Prostate. 2003; 54: 34-43.

25. Cherciu I, Barbalan A, Pirici D, Margaritescu C, Saftoiu A. Stem cells, colorectal cancer and cancer stem cell markers correlations. Curr Health Sci J. 2014; 40: 153-161.

26. Clauditz TS, von Rheinbaben K, Lebok P, Minner S, Tachezy M, Borgmann K, Knecht R, Sauter G, Wilczak W, Blessmann M, Munscher A. Activated leukocyte cell adhesion molecule (ALCAM/CD166) expression in head and neck squamous cell carcinoma (HNSSC). Pathol Res Pract. 2014; 210: 649-655.

27. Yan M, Yang XH, Wang LZ, Clark D, Zuo H, Ye DX, Chen WT, Zhang P. Plasma membrane proteomics of tumor spheres identify CD166 as a novel marker for cancer stemlike cells in head and neck squamous cell carcinoma. Mol Cell Proteomics. 2013; 12: 3271-3284.

28. Nowell PC. The clonal evolution of tumor cell populations. Science. 1976; 194: 23-28.

29. Reya T, Morrison SJ, Clarke MF, Weissman IL. Stem cells, cancer, and cancer stem cells. Nature. 2001; 414: 105-111. 
30. Weidle UH, Eggle D, Klostermann S, Swart GW. ALCAM/CD166: cancer-related issues. Cancer Genomics Proteomics. 2010; 7 : 231-243.

31. Lorch JH, Posner MR, Wirth LJ, Haddad RI. Seeking alternative biological therapies: the future of targeted molecular treatment. Oral Oncol. 2009; 45: 447-453.

32. Dziadziuszko R, Merrick DT, Witta SE, Mendoza AD, Szostakiewicz B, Szymanowska A, Rzyman W, Dziadziuszko K, Jassem J, Bunn PA Jr, Varella-Garcia M, Hirsch FR. Insulin-like growth factor receptor 1 (IGF1R) gene copy number is associated with survival in operable non-small-cell lung cancer: a comparison between IGF1R fluorescent in situ hybridization, protein expression, and mRNA expression. J Clin Oncol. 2010; 28: 2174-2180.

33. Yuan YL, Zhou XH, Song J, Qiu XP, Li J, Ye LF. Dual silencing of type 1 insulin-like growth factor and epidermal growth factor receptors to induce apoptosis of nasopharyngeal cancer cells. J Laryngol Otol. 2008; 122: 952-960.

34. Golding SE, Morgan RN, Adams BR, Hawkins AJ, Povirk LF, Valerie K. Pro-survival AKT and ERK signaling from EGFR and mutant EGFRvIII enhances DNA double-strand break repair in human glioma cells. Cancer Biol Ther. 2009; 8: 730-738.

35. Grana TM, Sartor CI, Cox AD. Epidermal growth factor receptor autocrine signaling in RIE-1 cells transformed by the Ras oncogene enhances radiation resistance. Cancer Res. 2003; 63: 7807-7814.
36. Hatanpaa KJ, Burma S, Zhao D, Habib AA. Epidermal growth factor receptor in glioma: signal transduction, neuropathology, imaging, and radioresistance. Neoplasia. 2010; 12: 675-684.

37. Yulin Yuan P, MD XZ, Jian Song P, Xiaoping Qiu P, Jun Li M, Linfeng Ye M, Meng X, Xi D. Expression and clinical significance of epidermal growth factor receptor and type 1 insulin-like growth factor receptor in nasopharyngeal carcinoma. Ann Otol Rhinol Laryngol. 2008; 117: 192-200.

38. Shi W, Bastianutto C, Li A, Perez-Ordonez B, Ng R, Chow KY, Zhang W, Jurisica I, Lo KW, Bayley A, Kim J, O’Sullivan B, Siu L, et al. Multiple dysregulated pathways in nasopharyngeal carcinoma revealed by gene expression profilin. Int J Cancer. 2006; 119: 2467-2475.

39. Yuan L, Yi HM, Yi H, Qu JQ, Zhu JF, Li LN, Xiao T, Zheng Z, Lu SS, Xiao ZQ. Reduced RKIP enhances nasopharyngeal carcinoma radioresistance by increasing ERK and AKT activity. Oncotarget. 2016; 7: 11463-11477. doi: 10.18632/oncotarget.7201

40. Guo Y, Zhu XD, Qu S, Li L, Su F, Li Y, Huang ST, Li DR. Identification of genes involved in radioresistance of nasopharyngeal carcinoma by integrating gene ontology and protein-protein interaction networks. Int J Oncol. 2012; 40: 85-92.

41. Franken NA, Rodermond HM, Stap J, Haveman J, van Bree C. Clonogenic assay of cells in vitro. Nat Protoc. 2006; 1: 2315-2319. 